\title{
Zum Wiedererscheinen.
}

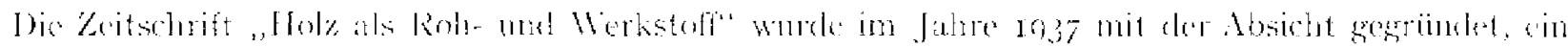

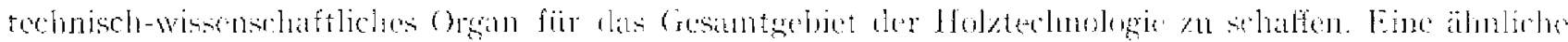

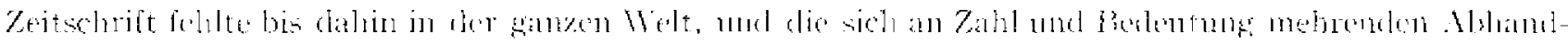

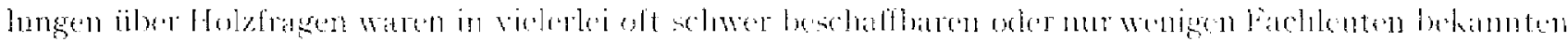
Zeilschrifion verstront.

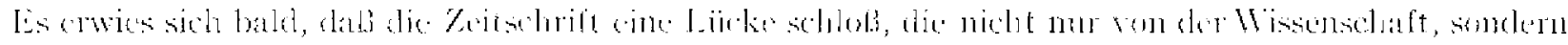

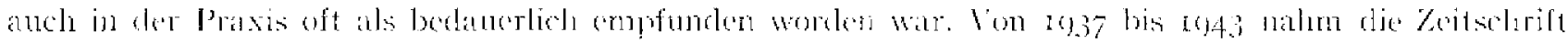

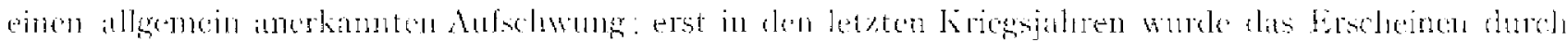

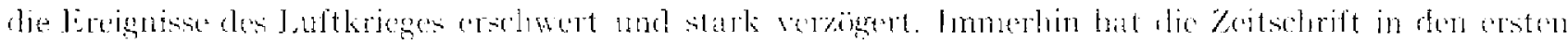

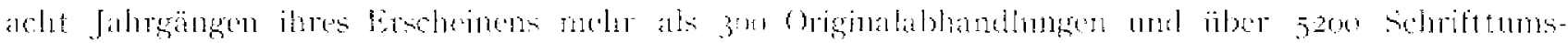
bericlite veriblinticht.

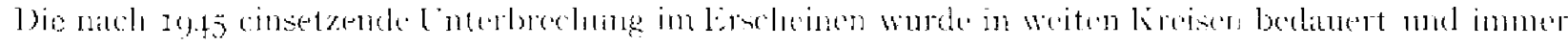

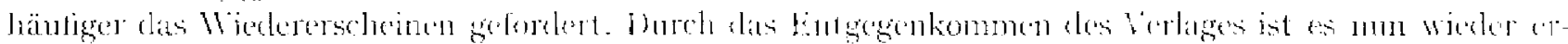

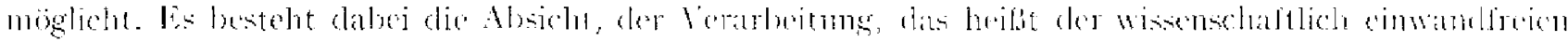

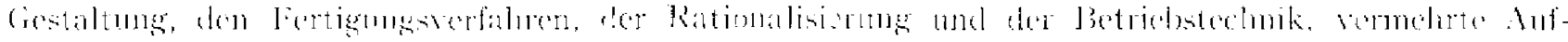
merkinmkint an shomken.

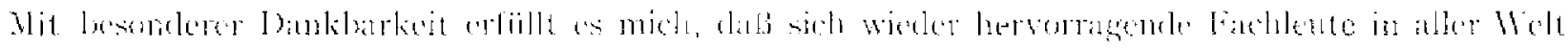

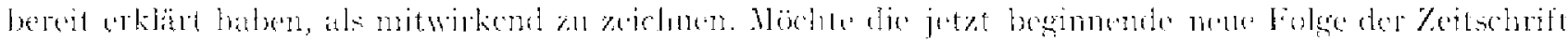

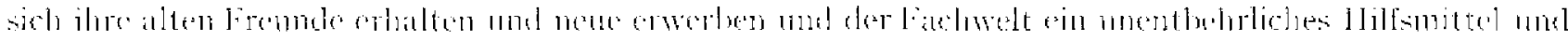

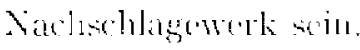

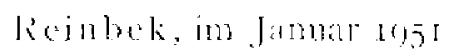

l'ref. Mr.-Ine. F. Kollmann.

\section{Spalten, Spaltbeanspruchung und Querfestigkeit des Holzes.}

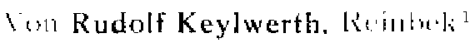

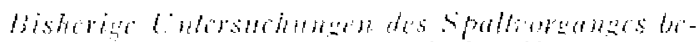

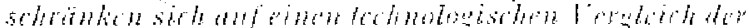

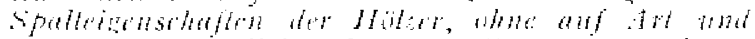

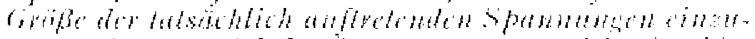

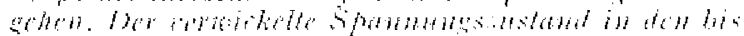

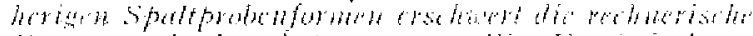

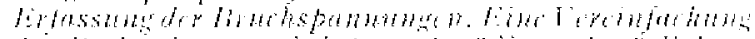

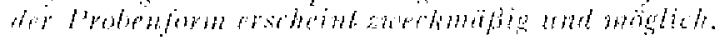

\section{Einleitung.}

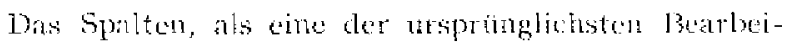
tangsaten des IJolzes, ist liente gegenubet anderen J3:-

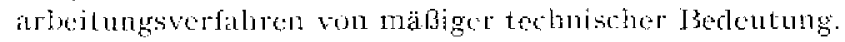
Wesentich wichtiger elagegen crscheint die bintersuchung cos Spaltrorganges in Hinblicle aul clic Spaltbanspru-

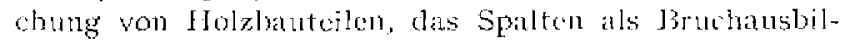

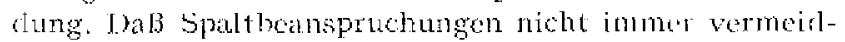

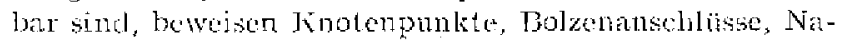
gelverbindungen u. the Die Spannumgsertetiung an solched Bauteilon ist - wic bei vielen Krafteinleitungon - Techt verwickel. Ihie Ermittlung ist cin bevorzugtes Aufgalengebiet der Spannungsoptik. Brauchbare Milaltspunkte lönuen jodoch auch aus Fostigkeits- und Hastizitälsunter suchungen an Wejkstoffproben gewonnen werden. Die bisherigen Prolueformen und clie verfigbaren Zahlenwerte der Spaltestigkeit und Ouerzuglestigkeit (t Holzfasor) t:

1 Die mitroteiluen Lintersuchungen wren $19 t 1$ in Mlo-

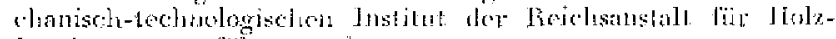
forschung ansefieiturt wortent.

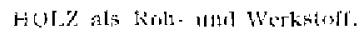

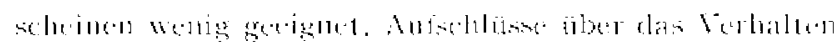

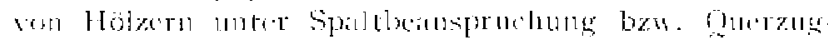

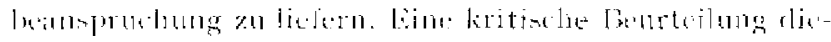

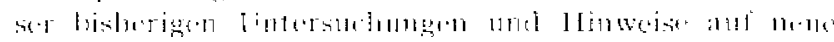

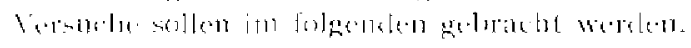

\section{Spalten, Spaltbcanspruchung.}

Tnter alem Spelterist chas l'eilen cinus Werkstotes tuit cinem kejarigor Werlazeds zu restehen, wobej jodoct: der Sohneide rles liejles eine - gegenuber anderen 130 -

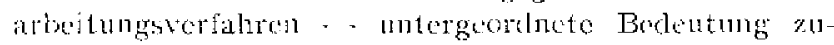

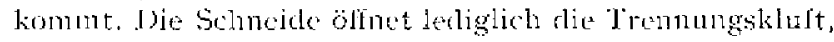

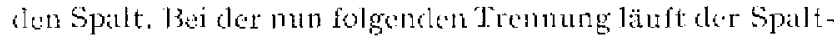

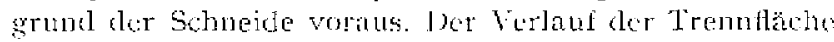
wird somit betm Spalton nur zu l3tginn vom Werkzoug allein bostimemt. Baim weiteren Trennvorgang sind die ortlichen Eigenschaten des Werkstoles maBgebend füt die

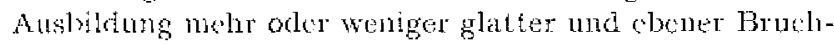
Aduchen. Olnetiachonbeschattenheit und Veriaut de Trom-

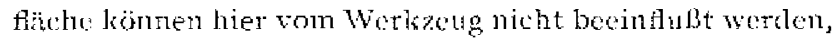

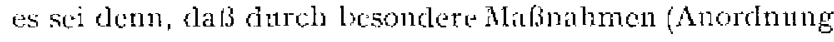
von 1)ruckleisten beim Schälen mal Messern des Holzes) cals Spalten überlaupt verhindert wird mel daher keine Spaltfachen, sonderin Sohnitufichen entstehen.

Hat die Wexlacugschneide clie sog. ,Urspalte" geollnot, so wird tie weitere Tremnung les Werlistickes von

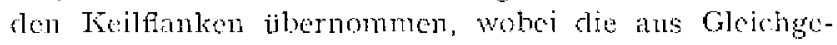

